\title{
Hybrid intelligence approach for multi-load level reactive power planning using VAR compensator in power transmission network
}

Nihar Karmakar ${ }^{*}$ (i) and Biplab Bhattacharyya

\begin{abstract}
This paper formulates and solves a techno-economic planning problem of reactive power (VAR) in power transmission systems under loadings. The objective of the proposed research work is to minimize the combination of installation cost of reactive power sources, power losses and operational cost while satisfying technical constraints. Initially, the positions for the placement of reactive power sources are determined technically. Different cost components such as VAR generation cost, line charging cost etc. are then added in the total operating cost in a most economical way. Finally, the optimal parameter setting subjected to reactive power planning (RPP) is obtained by taking advantages of hybrid soft computing techniques. For the justification of the efficiency and efficacy of the proposed approach the entire work is simulated on two inter-regional transmission networks. To validate the robustness and ease of the soft computing techniques in RPP the responses of benchmark functions and statistical proof are provided simultaneously.
\end{abstract}

Keywords: Active power loss, Reactive power planning, Hybrid algorithm, Line charging, Operating cost

\section{Introduction}

Electric power transmission operators and planners have had immense concern on the importance of reactive power in operation and planning problems. This concern originates from ever-increasing load demands, uncertainty in voltage stability and economic benefits by obeying the operational limits. Thus, reactive power has a considerable influence on economic as well as technical aspects of a power network.

Electric power systems require to be operated in a reliable and efficient manner considering reactive power control and voltage stability management. Reactive power margins are related to voltage stability and thus, reactive power planning (RPP) is one of the most challenging tasks and complex problems for power system researchers. RPP is divided into two categories viz. planning of VAR

* Correspondence: nihar.16dr000115@ee.ism.ac.in

Department of Electrical Engineering, Indian Institute of Technology (ISM), Dhanbad 826004, India

\section{Springer Open}

equipment installation and planning for system operation [1]. The objective of installation planning is to determine the location, size and type of reactive power compensators. On the other hand, the settings of voltage control devices such as capacitor banks, static compensators, synchronous compensators and open loop tap setting (OLTC) transformers are determined by system operation planning. Such preventive planning provides a stable, secure, reliable and economic power network [2].

In RPP there are many regular events such as demand, capacity and availability of power generating units and transmission limitations that extensively influence the system operating variables. In general these variables include active and reactive power flow through transmission lines, production of VAR in generators, tap positions of OLTC and the number of VAR sources to be installed in appropriate sizes. which permits use, sharing, adaptation, distribution and reproduction in any medium or format, as long as you give appropriate credit to the original author(s) and the source, provide a link to the Creative Commons licence, and indicate if changes were made. The images or other third party material in this article are included in the article's Creative Commons licence, unless indicated otherwise in a credit line to the material. If material is not included in the article's Creative Commons licence and your intended use is not permitted by statutory regulation or exceeds the permitted use, you will need to obtain permission directly from the copyright holder. To view a copy of this licence, visit http://creativecommons.org/licenses/by/4.0/. 


\subsection{Literature review}

In general, solutions for RPP problems are categorized into three groups as analytical approaches [3, 4], approaches by arithmetic programming and optimization techniques by meta-heuristic evolutionary optimizers. In the past few years, researchers have been addressing the RPP problems with the help of optimization techniques such as differential evolutionary (DE) algorithm [5], Genetic algorithm (GA) [6] etc. During RPP on a connected power network, an improved-particle swarm optimization (IPSO) after the basic particle swarm optimization (PSO) is implemented in [7] to lower the deficiency in searching space for the initial particles including boundary oscillations. In [8], a PSO based hybrid approach is presented to resist severe contingencies by effective reactive power reserve without perturbing system security. A meta-heuristic optimization algorithm viz. grey wolf optimization (GWO) is proposed in [9] to solve RPP problems in the IEEE test system.

Several classical approaches for RPP have also been reported. An integrated methodology is proposed in [2] for reactive power source expansion planning, while reference [10] uses successive LP (linear programing) to establish a satisfactory operation of power networks through loss minimization and lowering investment cost. Principles of Hamiltonian and Pontryagins as well as Benders' decomposition methods are implemented in [11] for optimal long-term RPP, while a cross-decomposition-algorithm (CDA) approach for RPP in multi-area large-scale power networks is reported in [12]. Mixed-integer Linear Programming (MILP) is applied in [13] for both RPP and transmission network expansion planning, and a deterministic non-linear model is adopted in [1] for long-term RPP.

Along with the aforementioned research, the operation of India's real power networks has been reported. To improve the voltage stability margin in an 82-node system in Indian, a non-linear least squares optimization approach is presented in [14]. This helps to lower the overall value of (L-indices $)^{2}$ in the case of vulnerable buses. A fuzzy rule based model is applied in an Indian power network to determine effective controllers and their movement directions with step size for the enhancement of system voltage profile [15]. In [16], voltage-collapse proximity based OPF as well as LP techniques are adopted for the improvement of bus voltages. A mathematical model of the Indian power system for the establishment of bidding protocol is proposed in [17], and in [18], conventional methods are presented to reduce congestion in the Indian power transmission system along with the transfer capability of the network. References $[19,20]$ reported different types of constraints such as security and environmental constraints etc. in the economic load dispatch (ELD) problem. Artificial intelligence (AI) techniques such as PSO are also used to determine the optimal VAR supporter size prior to the optimal power flow in [21,22].

\subsection{Aims and contributions}

Energy policy in India focuses on sustainable and rapid economic growth of the power sectors. To achieve this objective, the usage of energy at an affordable price along with the ancillary economic growth is of primary concern. However, low frequency $(48-49 \mathrm{~Hz})$ and low voltage $(0.7-$ 0.8 p.u) due to active-reactive power imbalance are some of the frequently occurring problems in Indian power networks [23]. In the existing literature, the system operating cost has not been considered for RPP in Indian power networks. These networks are also very prone to voltage instability and system collapse compared to other developed nations. In [14], only one method is adopted for assessing the voltage instability, while, proper measurement of voltage instability is very important prior to reactive power compensation. This paper presents a unique technoeconomic planning strategy for Indian power sectors to provide significant economic and sustainable benefits.

The proposed approach makes the following contributions:-

- Detection of critical/ weak nodes in Indian 62-bus and 191-bus systems by loss sensitivity analysis, power flow analysis and modal analysis method. These different methods are performed on the system to allow for proper compensation.

- Proper placement of VAR compensators with effective number and capacity to provide reactive power at weak nodes.

- Code profiling of different cost components using load multiplier parameters in practical Indian power networks to maintain a reliable operational cost structure.

- To obtain a global optimal solution extensive search has to be carried out in searching space. A, memory based hybrid algorithm is applied to tune controller parameters to minimize the system operating cost as well as power loss of the networks.

- Establishment of robustness of the hybrid-algorithm through the response of benchmark functions and statistical analysis.

\subsection{Paper organization}

This paper describes the mathematical outline of problem formulation and a brief explanation of the proposed methodology in Section II and III respectively. Results and details of the practical networks are illustrated in Section IV, while Section V address the statistical analysis of the optimized outcomes to measure the robustness of the proposed approach. Finally, an overall conclusion is given in Section VI. 


\section{Mathematical problem formulation}

In reactive power planning, power networks are treated as a set of equality and inequality constraints and better strategies are practiced to control the flow of active and reactive power. RPP is categorized as a non-linear complex problem, and the equation formulations of RPP in this paper are based on power loss minimization along with minimum system operating cost, $O C_{\text {total }}$ as:

$$
\begin{aligned}
& O C_{\text {total }}=C_{C r p}+C_{C s v c}+C_{C q g}+C_{C c h} \\
& C_{C r p}=P_{L} \times \text { rate of energy } \\
& =P_{L} \times(0.06 \times 100000 \times 24 \times 365) \\
& P_{L}=\sum_{k=(i, j)}^{m} g_{k}\left[V_{i}^{2}+V_{j}^{2}-2 V_{i} V_{j} \cos \left(\delta_{i}-\delta_{j}\right)\right] \\
& C_{C s v c}=0.0003\left(Q_{s v c}{ }^{2}\right)-30.3051\left(Q_{s v c}\right)+127.38 \\
& C_{C q g}=Q_{G} \times \text { rate of } Q-\text { generation cost } \\
& =Q_{G} \times(0.0068 \times 24 \times 365) \\
& Q_{G}=\sum_{k=1}^{n g}\left[a_{q} Q^{2}(k)+b_{q} Q(k)+c_{q}\right] \\
& \begin{array}{c}
C_{C c h}=Q_{c h} \times \text { per unit cost of reactive power during line ch arging } \\
=Q_{c h} \times 11.6068
\end{array} \\
& \left\{\begin{array}{c}
Q_{c_{i-j}}=V_{i}^{2} \frac{Y_{c h}}{2}+V_{j}^{2} \frac{Y_{c h}}{2} \\
Q_{c h}=\sum_{c h=1}^{N_{c h}} Q_{c_{i-j}}
\end{array}\right.
\end{aligned}
$$

Minimize,

$$
\begin{aligned}
O C_{\text {total }}= & \sum C_{C r p} \\
& +\left(\sum_{c=1}^{n_{c}} C_{C s v c}+\sum_{g=1}^{n g} C_{C q g}+\sum_{c h=1}^{N_{c h}} C_{C c h}\right)
\end{aligned}
$$

This paper aims to optimize the different reactive power sources such as transformer tap settings, generator reactive power output, capacitor bank etc. in a way that the system voltage profile is maintained within its limit at optimum operating conditions. Therefore, the supply of adequate reactive power is very important for maintaining the desired voltage stability. Generators are the main sources of reactive power. Reactive power pricing for generators is done using the triangle method [24] in this work, while the cost $\left(C_{C q g}\right)$ in (5) will encourage the reactive power producers to invest and provide more reactive power for system reliability. Total VAR generation $\left(Q_{G}\right)$ by synchronous generators is calculated in (6).
According to the study [25] the VAR cost during line charging by line charging reactance also makes up an essential part of the planning problem. So, $C_{C c h}$ is included as another VAR source in (7). Eq. (9) shows its additive nature; it can be considered as a split objective function in place of a multi-objective one. A better perception of the objective function can be obtained from Table 1 .

Usually the load flow balances in (10) and (11) are represented as the equality constraints. The inequality constraint (12) represents the upper-lower limits of voltage magnitude in all buses, while constraints (13) and (14) show the limits of VAR generation of generators and compensators respectively. The transformer tap-setting constraint is shown in (15).

$$
\begin{aligned}
& P_{G i}-P_{D i}-V_{i} \sum_{j=1}^{n_{b}} V_{j}\left[G_{i j} \cos \left(\delta_{i}-\delta_{j}\right)+B_{i j} \sin \left(\delta_{i}-\delta_{j}\right)\right] \\
& =0 \quad i \in N_{b} \\
& Q_{G i}-Q_{D i}-V_{i} \sum_{j=1}^{n_{b}} V_{j}\left[G_{i j} \sin \left(\delta_{i}-\delta_{j}\right)-B_{i j} \cos \left(\delta_{i}-\delta_{j}\right)\right]=0 \quad i \in N_{b} \\
& V_{i}^{\text {min }} \leq V_{i} \leq V_{i}^{\max } \quad i \in N_{b} \\
& Q_{G i}^{\min } \leq Q_{G i} \leq Q_{G i}^{\max } \quad i \in N_{g} \\
& Q_{c i}^{\text {min }} \leq Q_{c i} \leq Q_{c i}^{\max } \quad i \in N_{c} \\
& \operatorname{tap}_{i}^{\text {min }} \leq \operatorname{tap}_{i} \leq \operatorname{tap}_{i}^{\max } \quad i=N_{\text {tap }}
\end{aligned}
$$

\section{Proposed methodology}

From previous sections it is evident that RPP is difficult to solve directly. Also the problem formulation is a mixture of non-linear equations for which global optimized set of controlling parameters cannot be achieved by only implementing a conventional optimization approach. Thus, the solution of RPP is obtained by the following sub-strategies.

\subsection{Detection of weak nodes}

Optimal placement of VAR compensators is an important task for power system planners, both for operational and economic aspects. So this paper initially detects the weak positions for the placement of shunt compensators prior to the sizing of the devices. Three effective methods viz. loss sensitivity analysis (LSA) [26], power flow analysis (PFA) [27] and modal analysis (MA) [28] are applied for the detection of weak nodes.

\subsection{Modeling of static VAR compensator (SVC)}

SVC is a combination of thyristor controlled reactors and fixed capacitor banks. When connected parallel in 
Table 1 Comprehensive representation of cost amalgamated split objective function

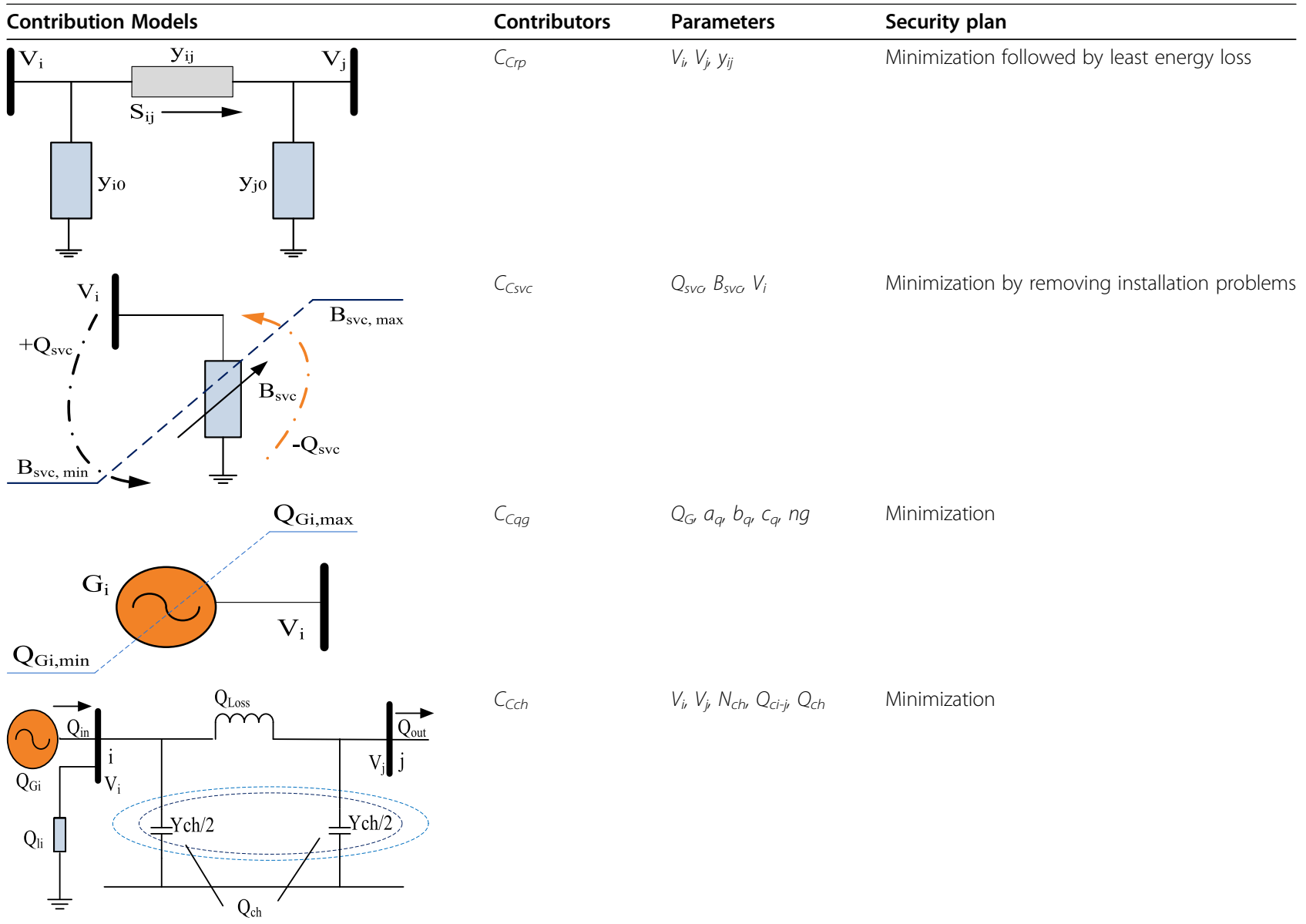

line, the reactive current is drawn from the source and the thyristor valves add or remove shunt connected reactors and capacitors. SVC injects VAR to a bus as: $Q_{s v c_{i}}$ $=B_{s v c} V_{i}^{2}$ where $V_{i}$ is the voltage magnitude and $B_{s v c}$ is the suceptance of the SVC connected at the $i^{\text {th }}$ bus. In this work, SVC is installed in this manner:

$$
\begin{aligned}
& \text { for } k=1: \operatorname{nsvc} \\
& \quad \operatorname{shunt}\left(\operatorname{pop} \_s v c(k)\right)=\operatorname{sqrt}(-1) * s v c_{-} \text {value } \\
& \text { end }
\end{aligned}
$$

where $n s v c$ and $s v c \_v a l u e$ are the number of SVC units and p.u susceptance value of the SVC unit respectively. After incorporating SVC units, the bus admittance matrix $\left(Y_{\text {bus }}\right)$, used for load flow analysis, is reformed as:

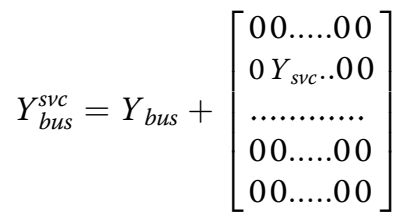

\subsection{Loadability enhancement}

Since the extent of RPP is wide, in a practical situation, the power networks face different echelons of load, and several transition states may occur under different loading conditions [29]. So, the aim of multi-load level RPP is to maintain a profile of minimum operating cost at minimum transmission loss without any violations of bus voltages. In this paper, loadability is formulated in terms of a single-valued scalar parameter $\lambda$, whose value is varied towards the maximum point, while the base load condition is identified when $\lambda=1$. Thereafter when the load is increased rather than for $\lambda$ to increase, the generator and load bus power (active and reactive) are updated as:

$$
\left\{\begin{aligned}
P_{G i} & =\lambda P_{G 0 i} \\
P_{L i} & =\lambda P_{L 0 i} \\
Q_{L i} & =\lambda Q_{L 0 i}
\end{aligned}\right.
$$

where $P_{G O i}, P_{L O i}$ and $Q_{L O i}$ are the initial $(\lambda=1)$ active and reactive power at the $\mathrm{i}^{\text {th }}$ bus, and their corresponding modified values are $P_{G i}, P_{L i}$ and $Q_{L i}$. 


\subsection{Application of evolutionary algorithms}

After addressing the technical aspects, some wellestablished evolutionary algorithms such as PSO, DE, CSA are used to search an optimal set of controlling parameters prior to solving the previously stated objective function. In this work the hybrid optimization method is adopted for the RPP problem. A unique hybridization between the crow search algorithm (CSA) and DE is simulated on a standard power system for RPP purpose. Some other algorithms are also applied to determine the optimized set of controlling parameters. In a later section, the hybridization is described briefly along with CSA and DE.

\subsubsection{Reasons for designing hybridization using DE and CSA} It is known from [30] that, no single optimizer exists which is able to determine a consistent solution to all global optimization problems. Based on this concept several attempts have been made on hybridization with core algorithms (e.g., PSO, DE, GA, CSA etc.) to handle the complexity in different engineering models. In many cases it is seen that the core algorithms fail to solve the non-linear complex problems after certain limitations. Thus, it is a good practice to adapt hybrid algorithms for an optimal result. In the hybridization method exploration and exploitation characteristics can be more effective when separate algorithms work simultaneously. It has already been shown in the previous discussions that RPP is a non-linear complex problem with different constraints and thus hybridization between CSA and DE is adopted to enhance the diversification and intensification of the controlling parameters for reactive power planning purposes. The adaptability of hybridization methods in power systems in recent years is listed in Table 2.

\subsubsection{Traditional DE [37]}

DE is technically a stochastic population based evolutionary algorithm. It uses three evolutionary operators viz. mutation, crossover and selection in a cycle towards the vicinity of an optimum individual solution from the randomly generated initial population. At initialization, a target vector (parents) $X_{i}=\left(x_{1 \dot{v}} x_{2 j} \ldots x_{d i}\right), i=1,2, . ., N P$ is randomly generated within user-defined limits of $d$ variables.

In Mutation, for each individual $X_{i}$, a mutate vector, $U_{i}(t+1)=\left(u_{1 i}(t+1), u_{2 i}(t+1), \ldots, u_{d i}(t+1)\right)$ is generated as:

$$
\begin{aligned}
& U i(t+1)=X r 1(t)+F *(X r 2(t)-X r 3(t) \\
& r l \neq r 2 \neq r 3 \neq i=1,2, \ldots, N P
\end{aligned}
$$

In Crossover, DE performs a crossover operation on parent and mutate vectors and thereafter a new trial vector (offspring) $V_{j i}(t+1)$ is obtained as:

$$
\begin{aligned}
& V_{j i}(t+1)=U_{j i}(t+1), \text { if } \operatorname{rand}(0,1) \leq C R \\
& X_{j i}(t), \text { otherwise }
\end{aligned}
$$

In Selection, the generated trial vector $V_{i}(t+1)$ will be compared with the parent vector $X_{i}(t)$ based on better fitness value, as:-

$$
\begin{aligned}
& X_{i}(t+1)=V_{i}(t+1), \text { if } f\left(V_{i}(t+1)\right) \leq f\left(X_{i}(t)\right) \\
& X_{i}(t), \text { otherwise }
\end{aligned}
$$

\subsubsection{Crow search algorithm [38]}

The crow search algorithm is a population based optimizer which is inspired by the intelligent behavior of crows for finding, storing and retrieving their food. In CSA, the individual position of every crow represents a possible solution of an optimization problem. At initialization the position vector of crows is represented in a string by $X^{i, i t e r}=\left[x_{1}^{i, i t e r}, x_{2}^{i, i t e r}, \ldots, x_{d}^{i, i t e r}\right]$-where $i$ ter $=1,2$, ..., itermax. Due to intelligence, each crow can memorize their best food storing places, and the memory locations

\begin{tabular}{|c|c|c|c|}
\hline Year & Reference & Hybrid Algorithm & Reason for implementation \\
\hline 2017 & {$[31]$} & $\begin{array}{l}\text { Chaotic Artificial Bee Colony Differential } \\
\text { Evolution (CABC-DE) algorithm }\end{array}$ & $\begin{array}{l}\text { To solve reactive power optimization and minimize the searching time for the } \\
\text { global solution. }\end{array}$ \\
\hline 2020 & [32] & Hybrid MGWO-SCA-CSA & $\begin{array}{l}\text { To reduce the overall generation cost of micro-grid system with the help of opti- } \\
\text { mal controlling parameters. }\end{array}$ \\
\hline 2017 & [33] & Hybrid of modified PSO and GA & $\begin{array}{l}\text { To solve non-linear optimal power flow problem in power system by enhancing } \\
\text { the primary population set generation procedure of the variables. }\end{array}$ \\
\hline 2020 & [34] & Hybrid PSODE & To determine the optimal solution of RPP in power transmission system. \\
\hline 2013 & [35] & Hybrid PSO & $\begin{array}{l}\text { To improve movements of particles and avoid local optimum solution subjected } \\
\text { to achieve economic benefits in community micro-grid operation. }\end{array}$ \\
\hline 2020 & [36] & $\begin{array}{l}\text { Hybrid Symbiotic Differential Evolution Moth- } \\
\text { flame Optimization (HSDE-MFO) algorithm }\end{array}$ & $\begin{array}{l}\text { To obtain optimal parameters of photovoltaic models depending upon } \\
\text { measured current-voltage data of photovoltaic systems for the reliable operation } \\
\text { of the system. }\end{array}$ \\
\hline
\end{tabular}
of crow i, $M^{i, i t e r}=\left[m_{1}^{i, i t e r}, m_{2}^{i, i t e r}, \ldots, m_{d}^{i, i t e r}\right]$ indicate the best food locations of that particular crow. In every iteration crow i also moves randomly to find the better sources of food (hidden places of other crows) by

Table 2 Different hybridization methods 


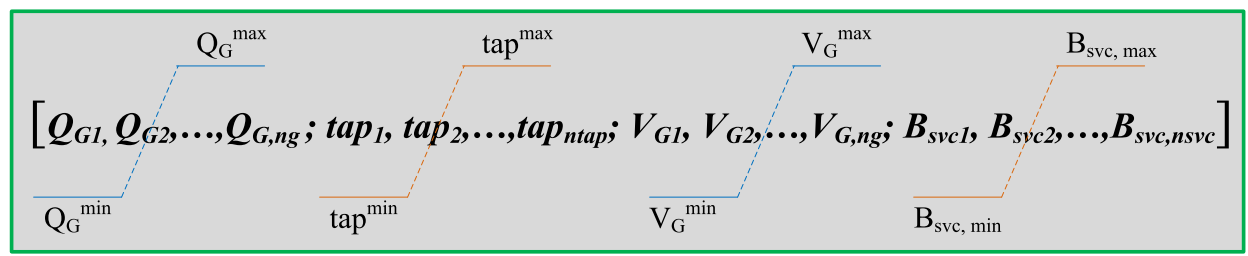

Fig. 1 String representation of population vector

following the randomly selected $\mathrm{j}^{\text {th }}$ crow and then acquires the best hiding place $\left(M^{j, i t e r}\right)$ corresponding to crow $\mathrm{j}$.

In accordance with some of the possibilities, the next position and hidden place (memory) of crow $\mathrm{i}$ is determined by:

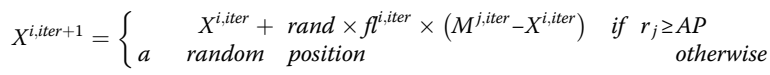

$$
\begin{aligned}
& M^{i, i t e r+1}=\left\{\begin{array}{lc}
X^{i, i t e r+1} & \text { if } f\left(X^{i, i t e r+1}\right) \text { is better than } f\left(M^{i, \text { iter }}\right) \\
M^{i, i t e r} & \text { otherwise }
\end{array}\right.
\end{aligned}
$$

\subsubsection{Hybrid DECSA}

It is seen from (19) and (20) that CR and F have a great impact on DE. In other words, crossover and mutation are the dominant operators, and thus, CR and F can be varied over a certain range in searching space. Also in CSA, memories of hidden food places play an important role for new search spaces. In hybrid DECSA, after mutation and crossover of the initial population a swarm set is generated using (19), (20) and (21). This elicited swarm is used as the best memory of crows to determine the next position of the crows using (22) in a cyclic process. A pseudo code of DECSA is given in algorithm 1.

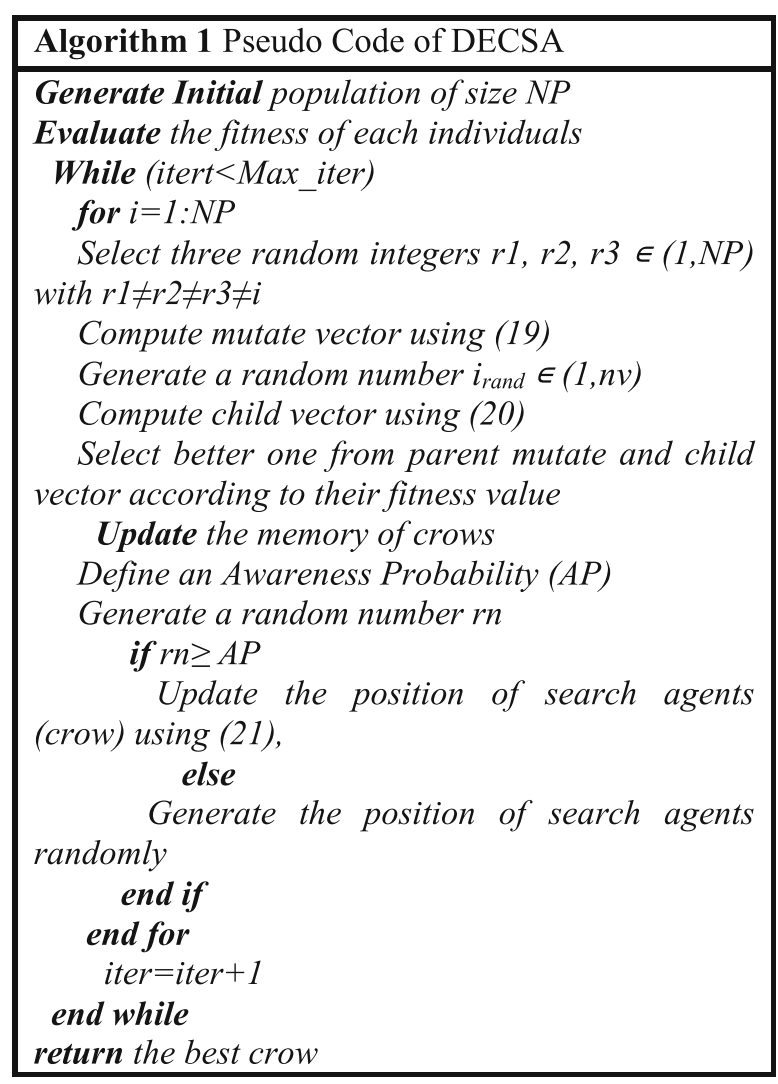

Table 3 Details of benchmark-test-functions [39]

\begin{tabular}{|c|c|c|c|c|}
\hline Benchmarks & Range & Functions & Type & GOV \\
\hline Sphere & {$[-100,100]$} & $f(u)=\sum_{i=1}^{d} u_{i}^{2}$ & UM & 0 \\
\hline Step & {$[-100,100]$} & $f(u)=\sum_{i=1}^{d}\left(u_{i}+0.5\right)^{2}$ & UM & 0 \\
\hline Dejong's & {$[-1.28,1.28]$} & $f(u)=\sum_{i=1}^{d}\left[i u_{i}^{4}+\operatorname{rand}(0,1)\right]$ & UM & 0 \\
\hline Ackley's & {$[-32,32]$} & $f(u)=-20 \exp \left(-0.2 \sqrt{\frac{1}{d} \sum_{i=1}^{d} u_{i}^{2}}\right)-\exp \left(\frac{1}{d} \sum_{i=1}^{d} \cos \left(2 \pi u_{i}\right)\right)+20+e$ & $\mathrm{MM}$ & 0 \\
\hline Griwank & {$[-600,600]$} & $f(u)=\sum_{i=1}^{d} \frac{u_{i}^{2}}{4000}-\prod_{i=1}^{d} \cos \left(\frac{u_{i}}{\sqrt{i}}\right)+1$ & $\mathrm{MM}$ & 0 \\
\hline Schwefel's & {$[-500,500]$} & $f(u)=\sum_{i=1}^{d}\left[100\left(x_{i+1}-x_{i}^{2}\right)^{2}+\left(x_{i}-1\right)^{2}\right]$ & $\mathrm{MM}$ & 0 \\
\hline
\end{tabular}


The population vector of the controlling parameters related to RPP used in this paper is presented in Fig. 1.

The numerical efficiency of DECSA is explored by solving classical benchmark functions. The details of these functions are given in Table 3 and the results of the comparison of different optimization techniques correspond to benchmark functions are shown in Table 4. A complete flow is shown in Fig. 2 in section IV.

It can be concluded from the convergence graphs of benchmark functions; in Figs. 3 and 4 that DECSA converges faster than DE and CSA. Also, it is an effort to measure the stability of hybrid DECSA to minimize the optimization problems.

\section{Results and discussion}

The proposed work is tested using MATLAB_2013a on a $\mathrm{PC}$ with a $3 \mathrm{GHz}$ processor. The weak nodes/ buses are shown in Table 4 . The weak nodes/ buses for the two Indian power networks are shown in Table 5.

\subsection{System 1: Indian 62-bus network}

This system is structured with 62 electrical buses, 89 lines, 18 generators and $11 \mathrm{OL} \mathrm{TC}$. The Indian 62-bus network information obtained from the literature is shown in Table 6.

Initially, $\mathrm{P}_{\mathrm{L}}$ and $\mathrm{OC}_{\text {total }}$ are $77.62 \mathrm{MW}$ and $4.0844 \times$ $10^{7} \$$ without RPP. Table 7 displays the numerical values in terms of $\mathrm{P}_{\mathrm{L}}$ and $\mathrm{OC}_{\text {total }}$ obtained from different evolutionary algorithms when the positions for SVC placement are determined by LSA, power flow analysis and MA, respectively. It is seen that hybrid DECSA and LSA co-operatively produce minimum $\mathrm{P}_{\mathrm{L}}$ and total operational cost (O.C) of 0.7057 p.u and $3.7080 \times 10^{7}$ \$, respectively.

The previous section has shown that the scaling factor $\mathrm{F}$ and cross-over ratio $\mathrm{CR}$ have a great impact on the DE algorithm. To comprehend the effect of controlling parameters, as tabulated in Table 7 , on $\mathrm{OC}_{\text {total }} 30$ individual runs are performed with 1000 iterations while these two parameters are varied from 0.1 to 0.9. From Table 7 it is seen that $\mathrm{OC}_{\text {total }}$ reduces to $3.7080 \times 107 \$$ at $C R=0.7$ and $F=0.6$ while the population size is forty.

Table 8 shows the numerical values in terms of $\mathrm{P}_{\mathrm{L}}$ and $\mathrm{OC}_{\text {total }}$ obtained from PSO, DE, DECSA etc. while buses for SVC placement are determined from previously mentioned analysis. It is observed that the minimum $\mathrm{P}_{\mathrm{L}}$ and total $\mathrm{OC}$ are 0.7057 p.u and $3.7080 \times 10^{7} \$$, respectively. From Table 9, the effect of load alteration on $\mathrm{P}_{\mathrm{L}}$ and O.C on the 62-bus system can be noted. System 1 is able to transmit power up to $130 \%$ loading under the proposed arrangement. The reduction in $\mathrm{P}_{\mathrm{L}}$ is up to $9.58 \%$ and O.C $1.4916 \times 10^{7}$ with respect to no planning on the system. At $110 \%, 120 \%$ and $130 \%$ loading levels the power losses are minimized to 1.2209 p.u., 1.9605 p.u. and 3.1327 p.u respectively. After 130\% loading the system collapses because of the violations of system constraints.

Figure 5 draws the convergence performance of the evolutionary algorithms while weak positions are decided according to LSA. From these characteristics it is seen that the objective function value converges more evenly for the DECSA based strategy than PSO, DE, CSA, PSODE and PSOCSA.

Previous studies have proved that SVC has a great impact on the transmission system. The bar graphs in Fig. 6 show the relative contribution of VAR through SVC into System 1. According to the conditions of $\mathrm{RPP}$, the bus voltage must lie within predefined voltage limits. Figure 7 validates the previous statement while weak bus voltages are within the dotted range. The optimal values of the controlling parameters, responsible for the RPP problem are tabulated in Table 10. It is also noteworthy, from the table that all the optimal controlling parameters are within permissible limits.

Table 4 Comparison of optimization results obtained for the benchmark functions

\begin{tabular}{|c|c|c|c|c|c|c|}
\hline \multirow[t]{2}{*}{ Algorithm } & \multicolumn{2}{|l|}{ Sphere } & \multicolumn{2}{|l|}{ Step } & \multicolumn{2}{|l|}{ Dejong's } \\
\hline & Mean & Std & Mean & Std & Mean & Std \\
\hline$D E[40]$ & $8.2 \mathrm{E}-14$ & $5.9 \mathrm{E}-14$ & 0 & 0 & 0.00463 & 0.0012 \\
\hline CSA[studied] & 0.0397 & $1.8448 \mathrm{E}-04$ & 0.0391 & $2.9843 \mathrm{E}-04$ & 0.0018 & 1.0877E-04 \\
\hline DECSA[proposed] & 0.0113 & $9.9770 \mathrm{E}-05$ & 0.0395 & 5.9997E-05 & 0.0014 & 2.0786E-04 \\
\hline \multirow[t]{2}{*}{ Algorithm } & \multicolumn{2}{|l|}{ Ackley's } & \multicolumn{2}{|l|}{ Griwank } & \multicolumn{2}{|l|}{ Schwefel's } \\
\hline & Mean & Std & Mean & Std & Mean & Std \\
\hline$D E[40]$ & 69.2 & 38.8 & 0 & 0 & 0 & 0 \\
\hline CSA[studied] & 0.0230 & $9.2361 \mathrm{E}-05$ & 0.0496 & $3.9056 \mathrm{E}-04$ & $-7.8924 \mathrm{E} 03$ & 62.22 \\
\hline DECSA[proposed] & 0.0113 & $5.2856 \mathrm{E}-05$ & 0.0393 & $8.0515 E-04$ & $-8.332 \mathrm{E} 03$ & 255.33 \\
\hline
\end{tabular}




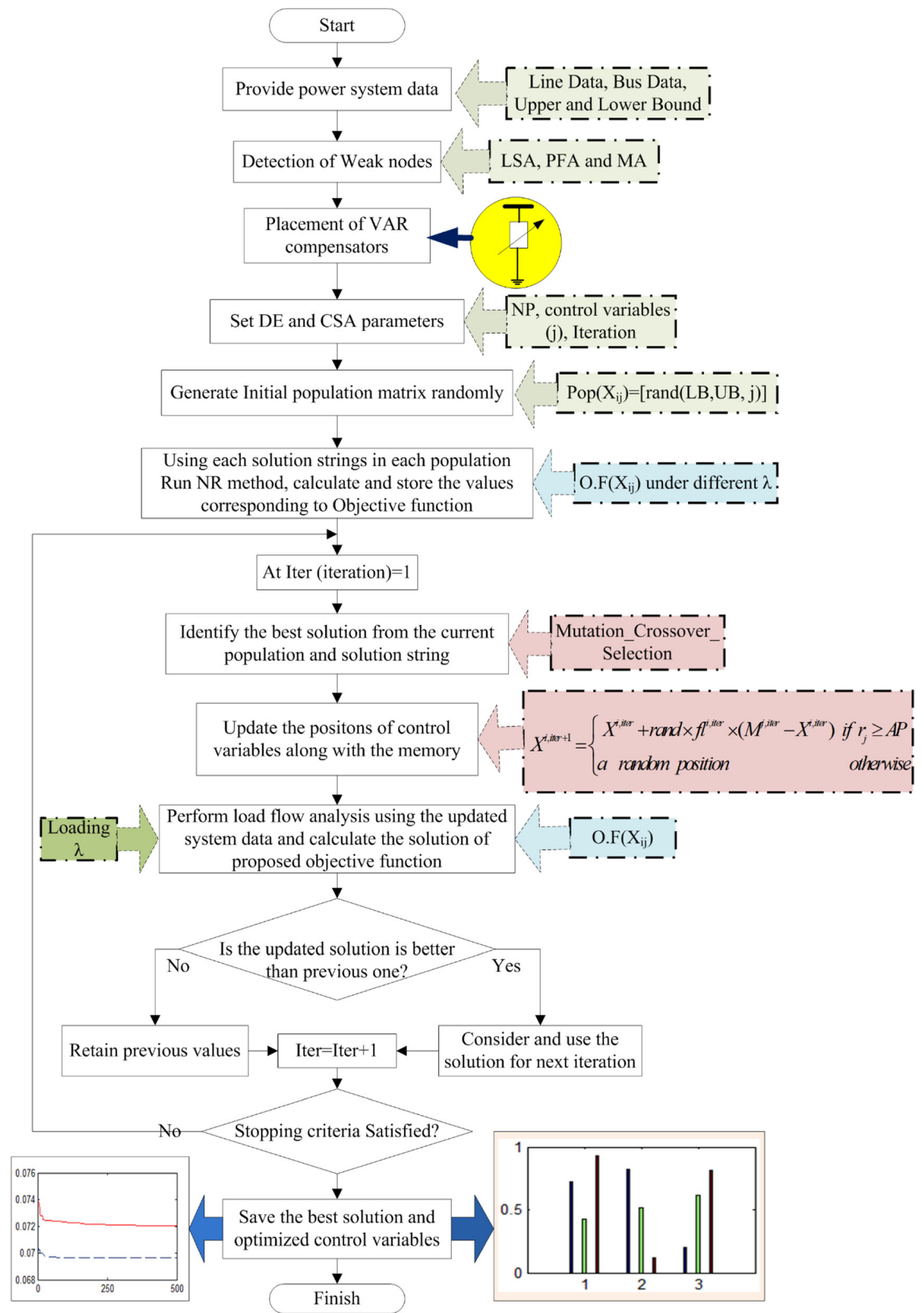

Fig. 2 Flow chart of proposed strategy for VAR Planning 

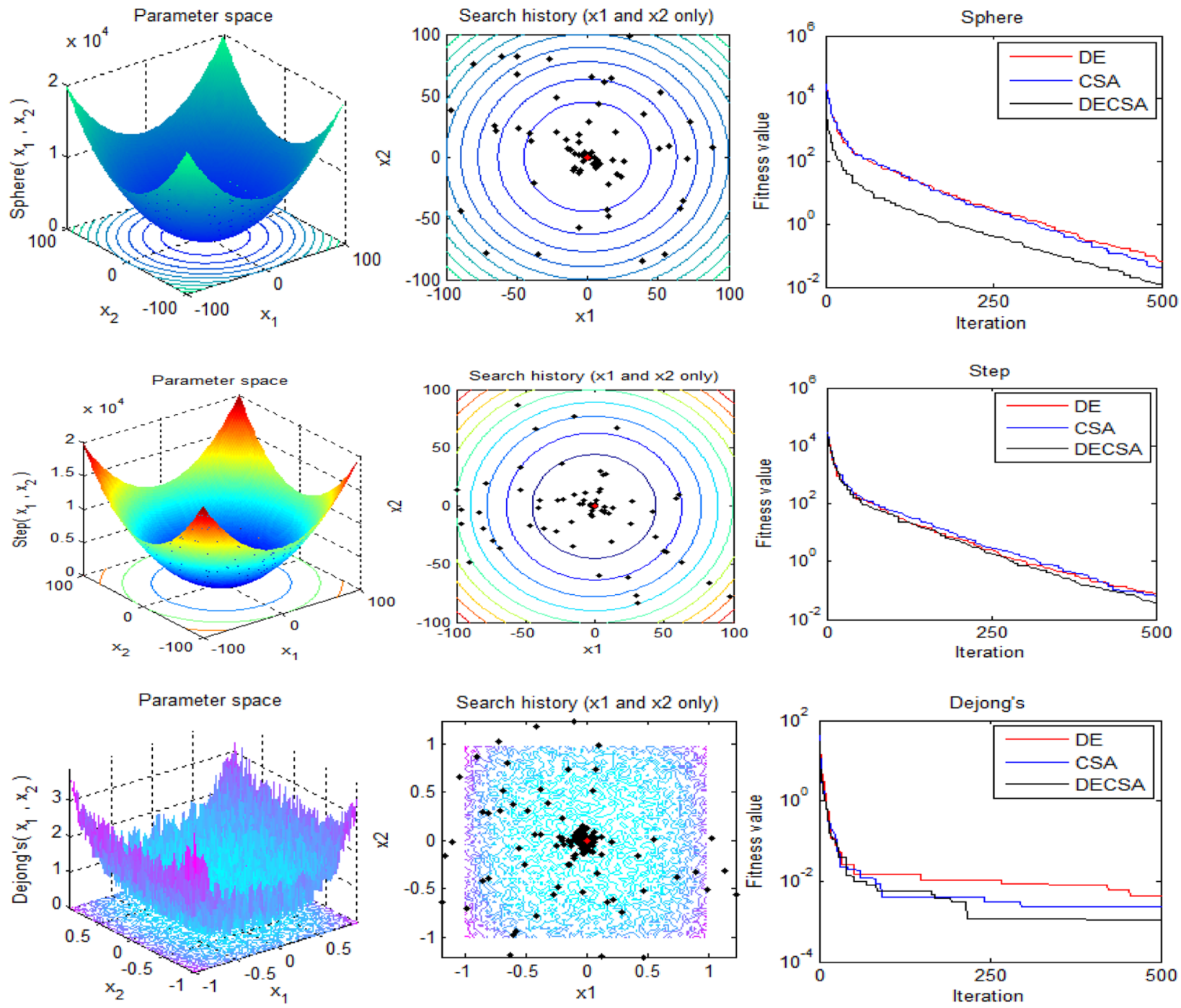

Fig. 3 Convergence characteristics of Uni-modal functions

Table 11 represents the frequency of attaining minimum loss within different ranges for System 1 from 30 independent trials. It can be seen that hybrid DECSA is the most robust of all the studied methods as it touches the minimum $\mathrm{P}_{\mathrm{L}} 26$ times out of the total 30. Figure 8 shows the bus voltages (V) after RPP at different load levels. This indicates that the voltages lie near to their permissible ranges except buses 19 and 18 (V19, V18) at 110\% loading.

\subsection{System 2: Indian 191 bus network}

The Indian 191-bus system is structured with 191 electrical buses, 255 lines, 19 generators, 55 OLTC, and the network information obtained from the literature is shown in Table 6. Initially, without RPP, $\mathrm{P}_{\mathrm{L}}$ and its operating cost are $93.70 \mathrm{MW}$ and $4.9284 \times$ $10^{7} \$$, respectively.

Table 12 shows the influence of cross-over ratio as well as mutation factor on hybrid DECSA. It can be seen that the operating costs are changed accordingly by changing $\mathrm{CR}$ and $\mathrm{F}$. It is found that the minimum operating is $4.673 \times 10^{7} \$$ at $\mathrm{CR}=0.8$ and $\mathrm{F}=0.6$.

Methods of weak bus detection have a great impact directly on $\mathrm{P}_{\mathrm{L}}$ and system operating cost which is reflected in Table 13. Similar to System 1, loss sensitivity analysis method provides a relatively better solution than others in the case of System 2. A pictorial representation of the convergence curve of operating cost, obtained from every optimization techniques, is shown in Fig. 9. The weak bus voltages shown in Fig. 10 also indicate that they are all within the dotted range. 

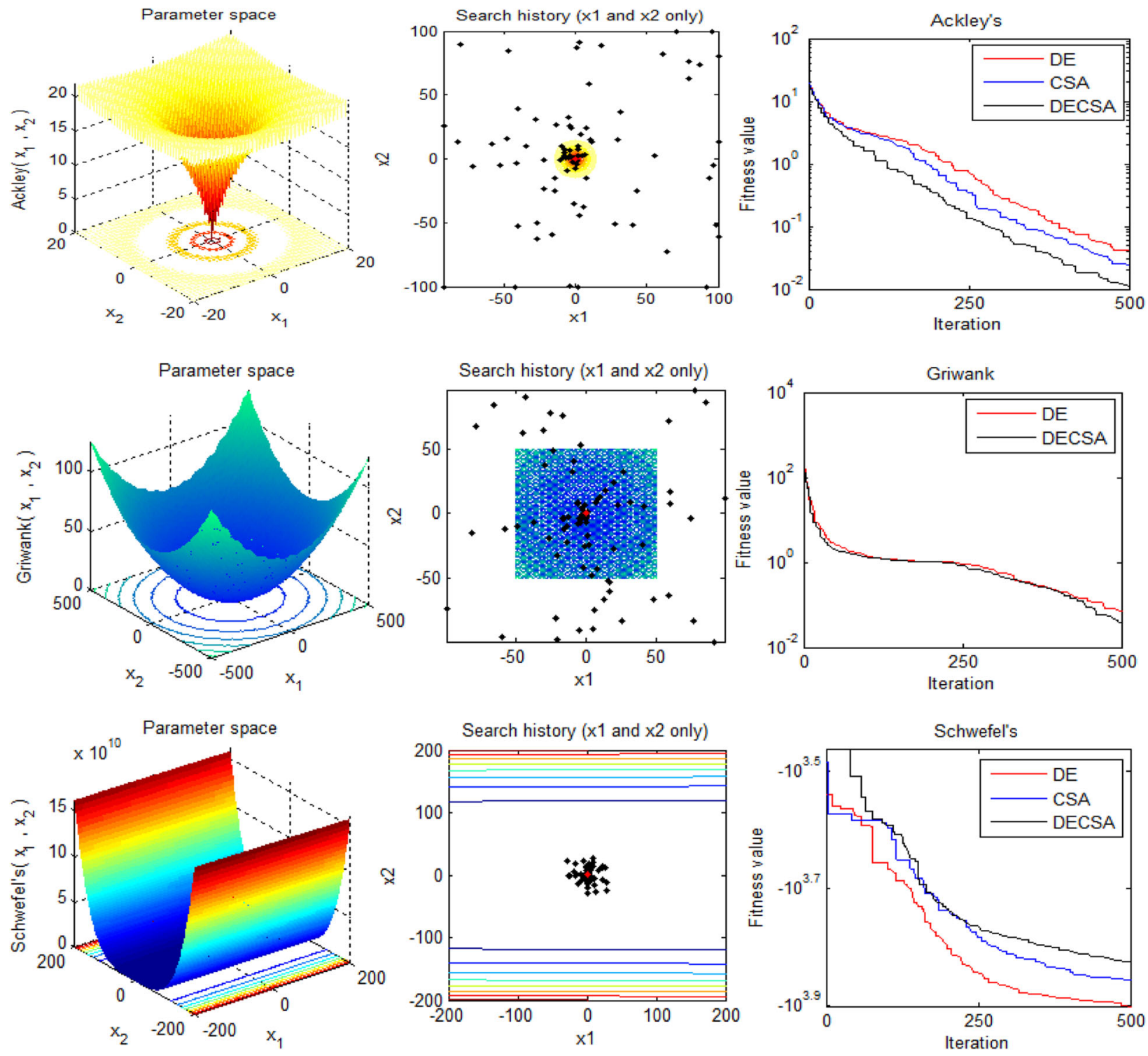

Fig. 4 Convergence characteristics of Multi-modal functions

The performance of DECSA is judged over a number of trials. Table 14 shows the convergence recurrence of minimum active power loss in the case of system 2. Here different ranges of possible solutions are decided for all the algorithms. It can be seen that

Table 5 Position of weak nodes/ buses for practical power networks

\begin{tabular}{lll}
\hline $\begin{array}{l}\text { Name of the bus } \\
\text { detection } \\
\text { techniques }\end{array}$ & \multicolumn{2}{l}{ Position of weak nodes at } \\
\cline { 3 - 3 } Indian 62-bus & \multicolumn{1}{l}{ Indian 191-bus } \\
\hline Loss sensitivity analysis & $6,44,36,10$ & $52,51,50,155,87$ \\
Power flow analysis & $10,39,6,26$ & $53,48,60,52,26$ \\
Modal analysis & $24,45,59,44$ & $38,63,41,99,106$ \\
\hline
\end{tabular}

DECSA provides the minimum $\mathrm{P}_{\mathrm{L}} 22$ times in 30 trials.

Unlike System1, System 2 operates up to $110 \%$ loading in proposed planning strategy. When the load factor is increased to $110 \%$ the real power loss and O.C are 0.9603 p.u and $5.0512 \times 10^{7} \$$ respectively before RPP. Table 15 shows the effect of SVC positions on $\mathrm{P}_{\mathrm{L}}$ and O.C during load change.

From Fig. 11, it is seen that the bus voltages are not in the pre-specified range under $110 \%$ loading. When the $\lambda$ value is high the fluctuation of bus voltage is more prominent in System 2. So it can be concluded that system voltage stability is very affected by $\lambda$ under this proposed approach. The list of symbols is given in appendix (7.1). 
Table 6 Details of the practical test systems

\begin{tabular}{|c|c|c|c|c|}
\hline \multirow{3}{*}{$\begin{array}{l}\text { System } \\
\text { Specifications }\end{array}$} & \multicolumn{4}{|c|}{ Test Systems } \\
\hline & \multicolumn{2}{|c|}{ Indian 62-bus } & \multicolumn{2}{|c|}{ Indian 191-bus } \\
\hline & Value & Details & Value & Details \\
\hline $\begin{array}{l}\text { Total Nodes/ } \\
\text { Buses }\end{array}$ & 62 & [41] & 191 & {$[42]$} \\
\hline Total PV buses & 18 & [41] & 19 & {$[42]$} \\
\hline Slack Bus & 1 & at bus 1 & 1 & at bus 1 \\
\hline $\begin{array}{l}\text { Load buses } \\
(P Q) \text { voltage } \\
\text { limits }\end{array}$ & 43 & 0.95 to 1.1 p.u & 171 & 0.9 to1.1 p.u \\
\hline $\begin{array}{l}\text { Shunt } \\
\text { capacitors }\end{array}$ & 2 & at bus 11 and 41 & 10 & $\begin{array}{l}\text { at bus } 54,102,156, \\
163,164,187,188, \\
189,190 \text { and } 191\end{array}$ \\
\hline OLTC & 11 & $\begin{array}{l}\text { at line } 3,11,12, \\
13,14,37,38,39, \\
82,83 \text { and } 85\end{array}$ & 55 & - \\
\hline $\begin{array}{l}\text { Total control } \\
\text { parameters }\end{array}$ & 33 & - & 79 & - \\
\hline $\begin{array}{l}\text { VAr limits of } \\
\text { generators }\end{array}$ & $\begin{array}{l}\mathrm{Q}_{\min } \\
\mathrm{Q}_{\max }\end{array}$ & [43] & $\begin{array}{l}\mathrm{Q}_{\min ,} \\
\mathrm{Q}_{\max }\end{array}$ & {$[42]$} \\
\hline
\end{tabular}

\section{Statistical analysis of test results}

To judge the robustness of the proposed algorithm subjected to RPP, the Wilcoxon signed rank test [44] is performed on a sample solution set. If probability ( $p$-value) obtained is below 0.05 , it is considered to be proper evidence against the null hypothesis. It is also well known that the robustness of any algorithm can be established if it can characterized with statistical significance by making sufficient proof against the null hypothesis. Along with maximum, minimum, average and standard deviation (std) values

Table 7 Control of F and CR on DECSA for Indian 62 Bus practical system

\begin{tabular}{|c|c|c|c|c|c|c|c|c|c|}
\hline \multirow[t]{3}{*}{$F$} & \multicolumn{9}{|c|}{ Crossover ratio, CR } \\
\hline & $\overline{0.1}$ & 0.2 & 0.3 & 0.4 & 0.5 & 0.6 & 0.7 & 0.8 & 0.9 \\
\hline & \multicolumn{9}{|c|}{ Operating cost $\times 10^{7}$ (\$) } \\
\hline$\overline{0.1}$ & 3.844 & 3.868 & 3.820 & 3.811 & 3.844 & 3.811 & 3.820 & 3.851 & 3.807 \\
\hline 0.2 & 3.842 & 3.747 & 3.775 & 3.902 & 3.848 & 3.802 & 3.775 & 3.844 & 3.842 \\
\hline 0.3 & 3.830 & 3.835 & 3.787 & 3.836 & 3.809 & 3.784 & 3.815 & 3.833 & 3.794 \\
\hline 0.4 & 3.834 & 3.813 & 3.821 & 3.870 & 3.834 & 3.809 & 3.807 & 3.866 & 3.788 \\
\hline 0.5 & 3.830 & 3.800 & 3.833 & 3.907 & 3.852 & 3.749 & 3.821 & 3.817 & 3.852 \\
\hline 0.6 & 3.834 & 3.800 & 3.826 & 3.900 & 3.804 & 3.850 & 3.7080 & 3.839 & 3.863 \\
\hline 0.7 & 3.859 & 3.800 & 3.801 & 3.823 & 3.834 & 3.779 & 3.800 & 3.851 & 3.806 \\
\hline .0 & 3.834 & 3.838 & 3.835 & 3.840 & 3.859 & 3.857 & 3.824 & 3.817 & 3.872 \\
\hline 0.9 & 3.859 & 3.800 & 3.822 & 3.870 & 3.817 & 3.828 & 3.824 & 3.851 & 3.785 \\
\hline
\end{tabular}

the $p$-values calculated using this test are tabulated in Table 16.

In this paper, only the $p$-value of DECSA is given since it produces less operating cost with respect to the other six methods when subjected to RPP on practical networks. It is seen from Table 16 that the $p$-value in every system is less than the desired value of 0.05 which is in favor of statistical significance of the test results. Also, the standard deviation values for the test systems using the proposed algorithm are very low which indicates least deviation of the results in comparison to their mean values. Thus, it proves the robustness of the proposed algorithm in RPP.

Figures 12 and 13 represent the box plots of operating cost with different optimization techniques applied in the Indian 62-bus and 191-bus network respectively. These box-plots exhibit the distribution of quantitative data in a way that facilitates comparisons of $\mathrm{OC}_{\text {total }}$ from PSO, DE, CSA, PSODE and PSOCSA. It can be seen that the chances of obtaining minimum operating cost is very high since the median from DECSA is closer to the lower quartile.

\section{Conclusion}

This paper proposed a multi-load level RPP on Indian power systems. On two different networks the proposed planning strategy is capable of finding the optimal solutions of the objective function. The characteristic curve of hybrid DECSA smoothly converges to the verge of the optimal front and provides a better solution of the objective function than the other five studied algorithms. The algorithm maintains the solutions in a stochastic way and prespecified ranges in the search space. All SVCs are suitably placed with the locations determined using the LSA method by removing technical and computational bottlenecks. It is also noted that the overall operating costs of both systems are significantly reduced by the proposed approach in comparison to the base case scenario. Hence, it can be concluded that the proposed approach is suited to economic power planning with technical operations.

When different loading conditions are introduced in load flow analysis for both test systems it is noted that for System 1 the proposed approach yielded a significant solution for RPP whereas for System 2 it fails to provide a promising solution at higher load levels. Hence it is necessary to introduce an improved planning strategy for load adjustment. It may be solved by proper co-ordination of load flow parameters or by incorporating high performance VAR compensators to the system which may expand the horizon for future research in RPP. 


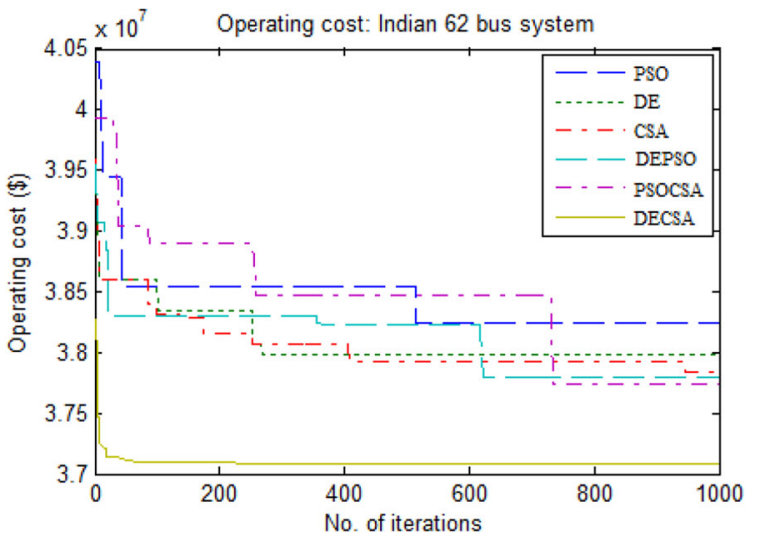

Fig. 5 Convergence behavior of OC from respective algorithms

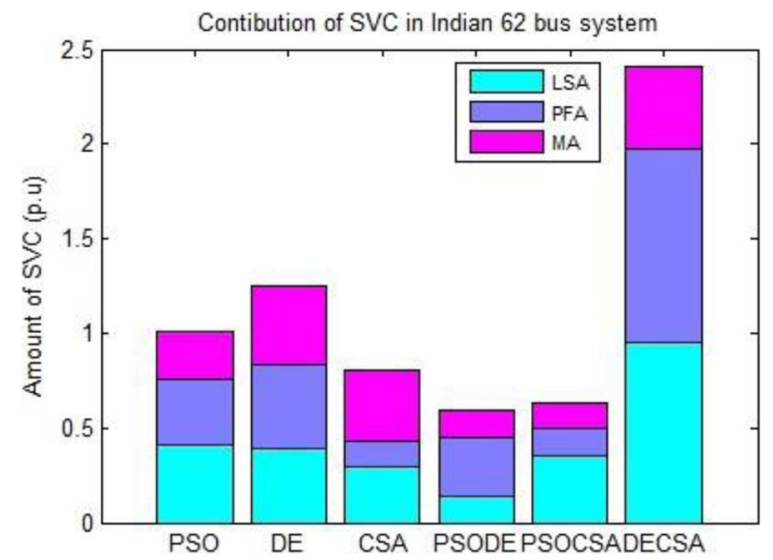

Fig. 6 Amount of SVC contributions at Weak nodes

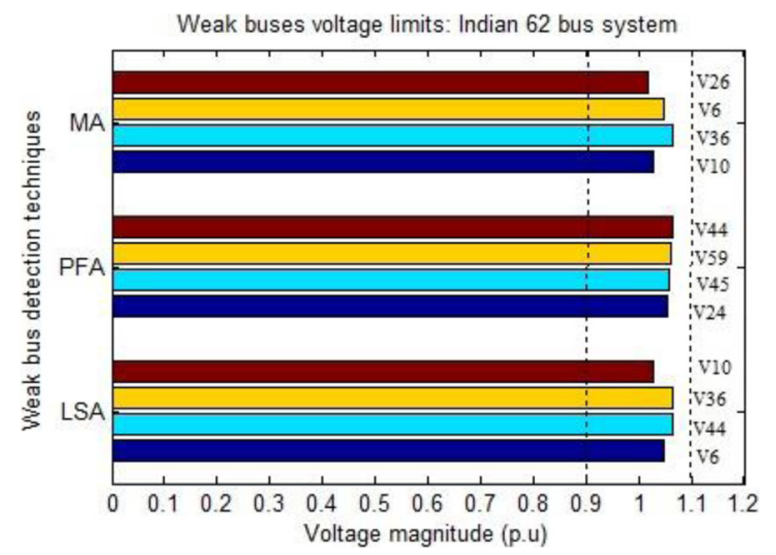

Fig. 7 Weak bus voltages after RPP

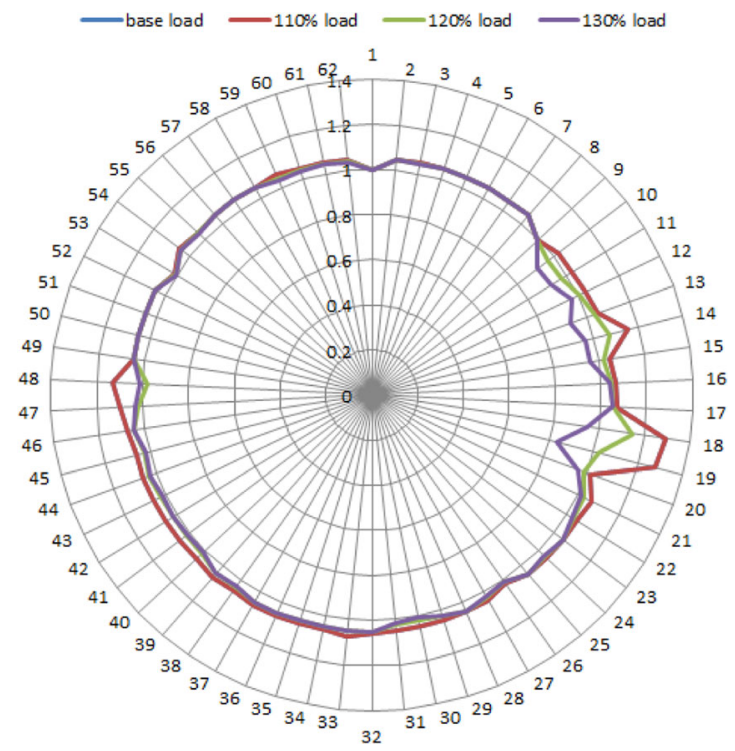

Fig. 8 Bus voltage profile under different loading conditions

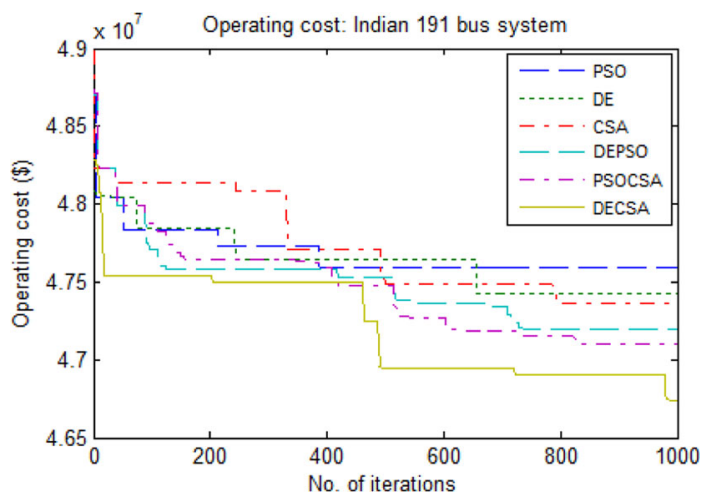

Fig. 9 Convergence behavior of OC from respective algorithms in System 2

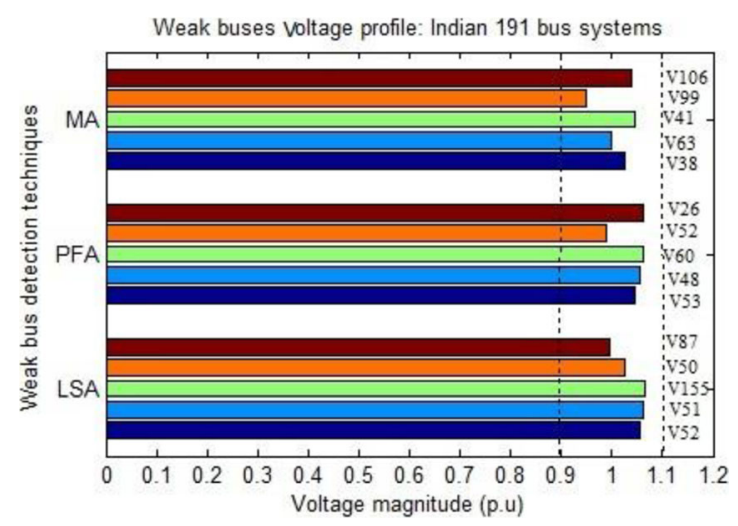

Fig. 10 Weak bus voltages after RPP 
Table 8 Optimal performance for Indian 62-bus practical system of three different methods

\begin{tabular}{|c|c|c|c|c|c|c|}
\hline \multirow[t]{2}{*}{ Methods } & \multicolumn{2}{|l|}{ LSA } & \multicolumn{2}{|l|}{ PFA } & \multicolumn{2}{|l|}{ MA } \\
\hline & $\begin{array}{l}\text { System real power } \\
\text { loss (in p.u) }\end{array}$ & $\begin{array}{l}\text { Minimum Operating } \\
\text { cost (in \$) }\end{array}$ & $\begin{array}{l}\text { System real power } \\
\text { loss (in p.u) }\end{array}$ & $\begin{array}{l}\text { Minimum Operating } \\
\text { cost (in \$) }\end{array}$ & $\begin{array}{l}\text { System real power } \\
\text { loss (in p.u) }\end{array}$ & $\begin{array}{l}\text { Minimum Operating } \\
\text { cost (in \$) }\end{array}$ \\
\hline$\overline{P S O}$ & 0.7240 & $3.80 \times 10^{7}$ & 0.7271 & $3.826 \times 10^{7}$ & 0.7286 & $3.83 \times 10^{7}$ \\
\hline$D E$ & 0.7217 & $3.79 \times 10^{7}$ & 0.7224 & $3.801 \times 10^{7}$ & 0.7242 & $3.811 \times 10^{7}$ \\
\hline CSA & 0.7191 & $3.78 \times 10^{7}$ & 0.7194 & $3.785 \times 10^{7}$ & 0.7199 & $3.791 \times 10^{7}$ \\
\hline PSODE & 0.7181 & $3.779 \times 10^{7}$ & 0.7184 & $3.78 \times 10^{7}$ & 0.7197 & $3.787 \times 10^{7}$ \\
\hline PSOCSA & 0.7172 & $3.77 \times 10^{7}$ & 0.7175 & $3.775 \times 10^{7}$ & 0.7175 & $3.775 \times 10^{7}$ \\
\hline DECSA & 0.7057 & $3.7080 \times 10^{7}$ & 0.7127 & $3.7479 \times 10^{7}$ & 0.7144 & $3.749 \times 10^{7}$ \\
\hline
\end{tabular}

Table 9 Effect of SVC allocation on Indian 62-bus system at multi-load levels

\begin{tabular}{|c|c|c|c|}
\hline Load & SVC positions & Reduction of $P_{L}$ in\% & Minimum O.C (\$) \\
\hline \multirow[t]{3}{*}{$100 \%(\lambda=1)$} & $6,44,36,10$ & 9.08 & $3.7080 \times 10^{7}$ \\
\hline & $10,39,6,26$ & 8.18 & $3.7479 \times 10^{7}$ \\
\hline & $24,45,59,44$ & 7.96 & $3.749 \times 10^{7}$ \\
\hline \multirow[t]{3}{*}{$110 \%$} & $6,44,36,10$ & 8.09 & $5.8969 \times 10^{7}$ \\
\hline & $10,39,6,26$ & 7.57 & $5.9301 \times 10^{7}$ \\
\hline & $24,45,59,44$ & 7.26 & $5.9501 \times 10^{7}$ \\
\hline \multirow[t]{3}{*}{$120 \%$} & $6,44,36,10$ & 8.57 & $9.4197 \times 10^{7}$ \\
\hline & $10,39,6,26$ & 8.11 & $9.4678 \times 10^{7}$ \\
\hline & $24,45,59,44$ & 7.96 & $9.4828 \times 10^{7}$ \\
\hline \multirow[t]{3}{*}{$130 \%$} & $6,44,36,10$ & 9.58 & $1.4916 \times 10^{7}$ \\
\hline & $10,39,6,26$ & 8.98 & $1.4985 \times 10^{7}$ \\
\hline & $24,45,59,44$ & 8.73 & $1.5026 \times 10^{7}$ \\
\hline
\end{tabular}

Table 10 Optimal system operating variables for System 1 with LSA and hybrid DECSA

\begin{tabular}{|c|c|c|c|c|c|c|}
\hline \multicolumn{3}{|c|}{ Reactive power of Alternators (p.u) $(*)$} & $\begin{array}{l}\text { VAr support by } \\
\text { SVC }(\text { p.u) }(*)\end{array}$ & \multicolumn{3}{|c|}{ OLTC Tap settings (\#) } \\
\hline \multicolumn{3}{|c|}{$\begin{array}{l}0(2), 0(4), 1.5(5), 0(8), 5(17), 0(23), 0(25), 0 \text { (32), } 0(33), 2 \\
(34), 0.75(37), 3(49), 2(50), 0(51), 0(52), 0(54), 4(57), 0 \text { (58) }\end{array}$} & $\begin{array}{l}0.5(4), 0.01(44) \\
0.01(36), 0.4329 \\
(26)\end{array}$ & \multicolumn{3}{|c|}{$\begin{array}{l}0.89 \text { (3), } 1.08 \text { (11), } 0.9018 \text { (12), } 0.9331 \text { (13), } 1.0028 \text { (14), } 0.89 \\
\text { (37), } 0.89 \text { (38), } 1.08 \text { (39), } 1.08 \text { (82), } 1.08 \text { (83), } 0.9246 \text { (85) }\end{array}$} \\
\hline \multicolumn{7}{|c|}{$\begin{array}{l}\text { *indicates bus number } \\
\text { \#indicates line number }\end{array}$} \\
\hline \multirow[t]{2}{*}{ Methods } & \multicolumn{6}{|c|}{ Range of active power loss, $P_{L}$ (p.u) } \\
\hline & $0.776-0.766$ & $0.766-0.756$ & $0.756-0.746$ & $0.746-0.736$ & $0.736-0.726$ & $0.726-0.696$ \\
\hline PSO & 0 & 0 & 1 & 4 & 8 & 17 \\
\hline DE & 0 & 0 & 2 & 1 & 10 & 17 \\
\hline CSA & 0 & 0 & 0 & 4 & 8 & 18 \\
\hline PSODE & 0 & 0 & 1 & 3 & 7 & 19 \\
\hline PSOCSA & 0 & 0 & 0 & 3 & 6 & 21 \\
\hline DECSA & 0 & 0 & 0 & 1 & 3 & 26 \\
\hline
\end{tabular}


Table 12 Control of F and CR on DECSA for the Indian 191-bus practical system

\begin{tabular}{|c|c|c|c|c|c|c|c|c|c|}
\hline \multirow[t]{3}{*}{$F$} & \multicolumn{9}{|l|}{$\mathrm{CR}$} \\
\hline & $\overline{0.1}$ & 0.2 & 0.3 & 0.4 & 0.5 & 0.6 & 0.7 & 0.8 & 0.9 \\
\hline & \multicolumn{9}{|c|}{ Operating $\cos t \times 10^{7}$} \\
\hline 0.1 & 4.762 & 4.754 & 4.748 & 4.750 & 4.711 & 4.750 & 4.710 & 4.74 & 4.717 \\
\hline 0.2 & 4.759 & 4.785 & 4.741 & 4.741 & 4.719 & 4.741 & 4.719 & 4.76 & 4.717 \\
\hline 0.3 & 4.757 & 4.769 & 4.785 & 4.757 & 4.779 & 4.76 & 4.757 & 4.76 & 4.716 \\
\hline 0.4 & 4.760 & 4.76 & 4.742 & 4.760 & 4.722 & 4.743 & 4.73 & 4.75 & 4.717 \\
\hline 0.5 & 4.75 & 4.757 & 4.773 & 4.75 & 4.773 & 4.769 & 4.75 & 4.710 & 4.722 \\
\hline 0.6 & 4.753 & 4.785 & 4.779 & 4.755 & 4.769 & 4.779 & 4.757 & 4.673 & 4.717 \\
\hline 0.7 & 4.717 & 4.781 & 4.773 & 4.779 & 4.749 & 4.785 & 4.73 & 4.688 & 4.729 \\
\hline 0.8 & 4.722 & 4.765 & 4.743 & 4.743 & 4.73 & 4.755 & 4.765 & 4.702 & 4.737 \\
\hline 0.9 & 4.74 & 4.755 & 4.754 & 4.741 & 4.755 & 4.754 & 4.761 & 4.691 & 4.721 \\
\hline
\end{tabular}

Table 13 Optimal performance for Indian 191-bus practical system of three different methods

\begin{tabular}{|c|c|c|c|c|c|c|}
\hline \multirow[t]{2}{*}{ Methods } & \multicolumn{2}{|l|}{ LSA } & \multicolumn{2}{|l|}{ PFA } & \multicolumn{2}{|l|}{ MA } \\
\hline & $\begin{array}{l}\text { System real power } \\
\text { loss (in p.u) }\end{array}$ & $\begin{array}{l}\text { Minimum Operating } \\
\text { cost (in \$) }\end{array}$ & $\begin{array}{l}\text { System real power } \\
\text { loss (in p.u) }\end{array}$ & $\begin{array}{l}\text { Minimum Operating } \\
\text { cost (in \$) }\end{array}$ & $\begin{array}{l}\text { System real power } \\
\text { loss (in p.u) }\end{array}$ & $\begin{array}{l}\text { Minimum Operating } \\
\text { cost (in \$) }\end{array}$ \\
\hline PSO & 0.9048 & $4.759 \times 10^{7}$ & 0.9051 & $4.760 \times 10^{7}$ & 0.9054 & $4.762 \times 10^{7}$ \\
\hline$D E$ & 0.9016 & $4.740 \times 10^{7}$ & 0.9037 & $4.751 \times 10^{7}$ & 0.9025 & $4.74 \times 10^{7}$ \\
\hline CSA & 0.9004 & $4.730 \times 10^{7}$ & 0.9008 & $4.737 \times 10^{7}$ & 0.9044 & $4.757 \times 10^{7}$ \\
\hline PSODE & 0.8971 & $4.719 \times 10^{7}$ & 0.8972 & $\times 10^{7}$ & 0.8976 & $4.721 \times 10^{7}$ \\
\hline PSOCSA & 0.8954 & $4.710 \times 10^{7}$ & 0.8967 & $4.717 \times 10^{7}$ & 0.8970 & $4.718 \times 10^{7}$ \\
\hline DECSA & 0.8884 & $4.673 \times 10^{7}$ & 0.8995 & $4.701 \times 10^{7}$ & 08990 & $4.716 \times 10^{7}$ \\
\hline
\end{tabular}

Table 14 Convergence recurrence of $P_{L}$ on the Indian 191-bus system from 30 trials

\begin{tabular}{lllll}
\hline Methods & \multicolumn{2}{l}{ Range of power loss, $\mathbf{P}_{\mathbf{L}}$ (p.u) } & & $\mathbf{0 . 9 1 7 - 0 . 9 0 7}$ \\
\cline { 2 - 5 } & $\mathbf{0 . 9 3 7 - 0 . 9 2 7}$ & $\mathbf{0 . 9 2 7 - 0 . 9 1 7}$ & 9 & 15 \\
\hline PSO & 1 & 5 & 7 & 16 \\
$D E$ & 1 & 6 & 9 & 18 \\
CSA & 0 & 3 & 8 & 18 \\
PSODE & 0 & 4 & 8 & 20 \\
PSOCSA & 0 & 2 & 7 & 22 \\
DECSA & 0 & 1 & 7 & 20 \\
\hline
\end{tabular}

Table 15 Comparison between SVC allocation and effects on System 2

\begin{tabular}{llll}
\hline Load level & SVC positions & Reduction of $\mathbf{P}_{\mathbf{L}}$ in $\%$ & Minimum $\mathbf{0 . C}(\mathbf{\text { S }}$ \\
\hline $100 \%$ & $52,51,50,155,87$ & 5.19 & $4.673 \times 10^{7}$ \\
$(\lambda=1)$ & $53,48,60,52,26$ & 4.00 & $4.701 \times 10^{7}$ \\
& $38,63,41,99,106$ & 4.06 & $4.716 \times 10^{7}$ \\
$110 \%$ & $52,51,50,155,87$ & 2.59 & $4.9145 \times 10^{7}$ \\
$(\lambda=1.1)$ & $53,48,60,52,26$ & 2.54 & $4.9171 \times 10^{7}$ \\
& $38,63,41,99,106$ & 2.5 & $4.9193 \times 10^{7}$ \\
\hline
\end{tabular}



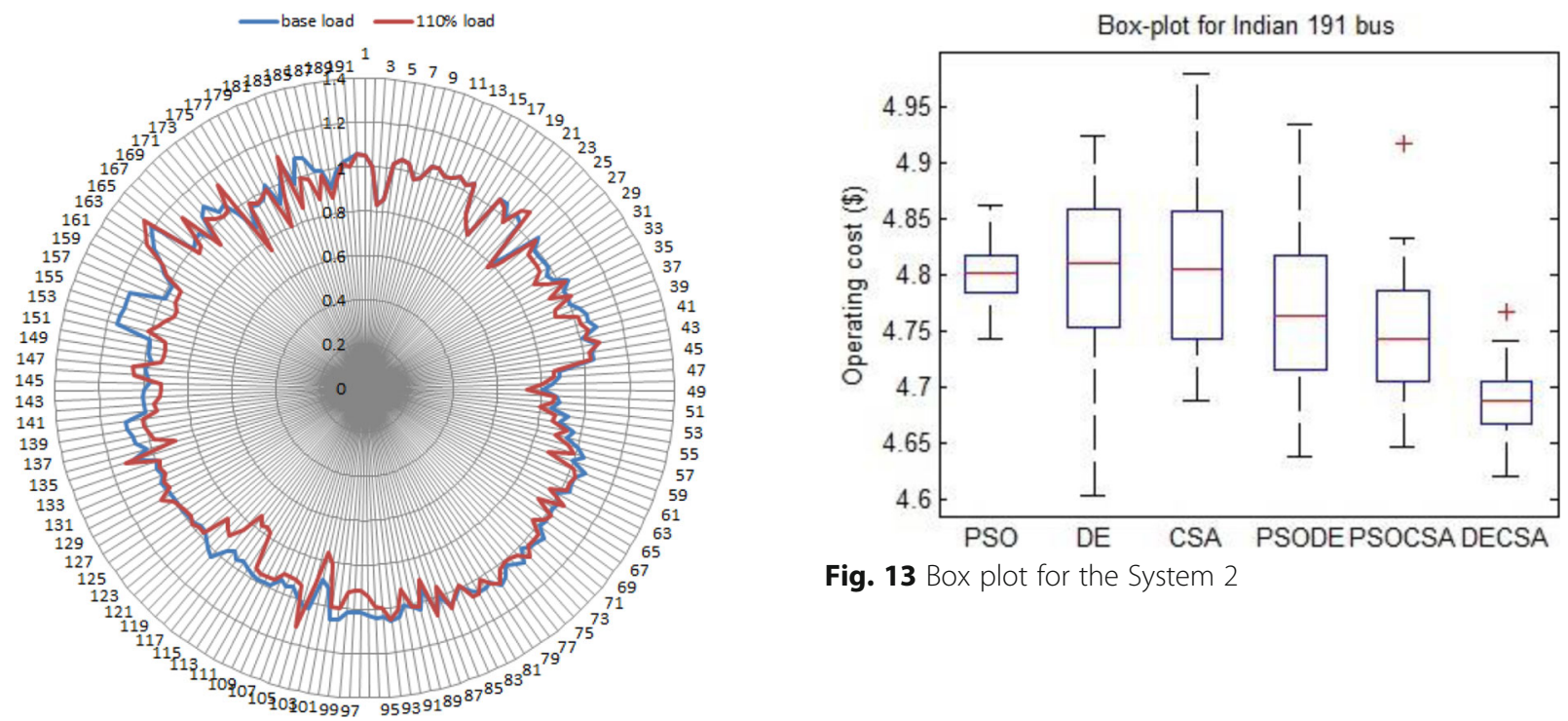

Fig. 13 Box plot for the System 2

Fig. 11 Bus voltage profile under different loading conditions

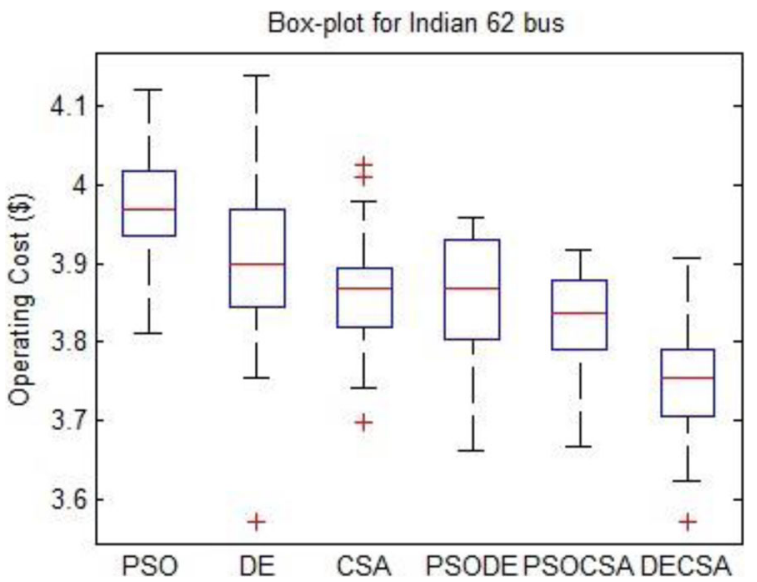

Fig. 12 Box plot for the System 1

Table 16 Wilcoxon signed rank test for statistical analysis

\begin{tabular}{|c|c|c|c|c|c|c|}
\hline Test System & Methods & Min. value (\$) & Mean value (\$) & Max. value (\$) & Standard deviation & $p$-value \\
\hline \multirow[t]{6}{*}{ Indian 62-bus } & PSO & $3.801 \times 10^{7}$ & $3.9574 \times 10^{7}$ & $4.192 \times 10^{7}$ & 0.1080 & - \\
\hline & $\mathrm{DE}$ & $3.790 \times 10^{7}$ & $3.9348 \times 10^{7}$ & $4.121 \times 10^{7}$ & 0.1207 & - \\
\hline & CSA & $3.781 \times 10^{7}$ & $3.8628 \times 10^{7}$ & $3.990 \times 10^{7}$ & 0.0730 & - \\
\hline & PSODE & $3.779 \times 10^{7}$ & $3.8582 \times 10^{7}$ & $3.989 \times 10^{7}$ & 0.0795 & - \\
\hline & PSOCSA & $3.770 \times 10^{7}$ & $3.8290 \times 10^{7}$ & $3.971 \times 10^{7}$ & 0.0764 & \\
\hline & DECSA & $3.708 \times 10^{7}$ & $3.7507 \times 10^{7}$ & $3.907 \times 10^{7}$ & 0.0719 & $6.9824 \times 10^{-7}$ \\
\hline \multirow[t]{6}{*}{ Indian 191-bus } & PSO & $4.759 \times 10^{7}$ & $4.7885 \times 10^{7}$ & $4.873 \times 10^{7}$ & 0.0203 & - \\
\hline & $\mathrm{DE}$ & $4.740 \times 10^{7}$ & $4.8142 \times 10^{7}$ & $4.934 \times 10^{7}$ & 0.0715 & - \\
\hline & CSA & $4.730 \times 10^{7}$ & $4.8004 \times 10^{7}$ & $4.930 \times 10^{7}$ & 0.0757 & - \\
\hline & PSODE & $4.719 \times 10^{7}$ & $4.7715 \times 10^{7}$ & $4.987 \times 10^{7}$ & 0.0630 & - \\
\hline & PSOCSA & $4.710 \times 10^{7}$ & $4.7576 \times 10^{7}$ & $4.880 \times 10^{7}$ & 0.0547 & - \\
\hline & DECSA & $4.673 \times 10^{7}$ & $4.6914 \times 10^{7}$ & $4.785 \times 10^{7}$ & 0.0302 & $1.0922 \times 10^{-6}$ \\
\hline
\end{tabular}




\section{Appendix}

\subsection{List of principal symbols}

\begin{tabular}{ll}
\hline Load flow and cost related symbols \\
$V_{i,} V_{j}$ & $i^{\text {th }}$ and $j^{\text {th }}$ bus voltages \\
$g_{k}$ & Line conductance \\
$\delta_{i}, \delta_{j}$ & $i^{\text {th }}$ and $j^{\text {th }}$ bus phase angles \\
$P_{G_{i}}, Q_{G_{i}}$ & Active and VAR generation at the $i^{\text {th }}$ bus \\
$P_{D_{i}}, Q_{D_{i}}$ & Active and VAR demand at the $i^{\text {th }}$ bus \\
$B_{i j}, G_{i j}$ & Susceptance and transfer conductance \\
$N_{c h}$ & Line charging elements \\
$Y_{c h}$ & Admittance of line charging \\
$Q_{c h}$ & Total reactive power supplied during charging \\
$n_{g}$ & Number of PV buses \\
$n_{b}$ & Total number of buses \\
$p_{. u}$ & Per unit \\
$a_{q}, b_{q}, C_{q}$ & Generator reactive power cost co-efficient \\
$C_{C r p}$ & Cost due to real power loss \\
$C_{C s v c}$ & Cost associated with SVC \\
$C_{C a g}$ & VAR generation cost of alternators \\
$C_{C c h}$ & Cost during line charging \\
$C$
\end{tabular}

Constraints and $Y_{\text {bus }}$ related symbols

\begin{tabular}{|c|c|}
\hline$V_{G}$ & Generator bus voltage \\
\hline$V_{G}^{\max }$ & Maximum limit of generator voltage \\
\hline$V_{G}^{\min }$ & Miniimum limit of generator voltage \\
\hline$Q_{G}$ & Generated reactive power \\
\hline$Q_{G}^{\max }$ & High limit of generated reactive power \\
\hline$Q_{G}^{\min }$ & Low limit of generated reactive power \\
\hline OLTC & Open loop tap changing transformers \\
\hline tap & Tap settings of OLTC \\
\hline $\operatorname{tap}^{\max }$ & Upper limit of tap setting \\
\hline $\operatorname{tap}^{\min }$ & Lower limit of tap settings \\
\hline$m$ & Number of lines \\
\hline$n_{\text {tap }}$ & Number of transformers \\
\hline$Y_{i i}$ & Sending end admittance \\
\hline$Y_{j j}$ & Receiving end admittance \\
\hline$V_{\text {sec }}$ & Transformer secondary voltage \\
\hline$I_{\text {sec }}$ & Transformer secondary current \\
\hline
\end{tabular}

Weak nodes and SVC related symbols

$\begin{array}{ll}Q_{S V C} & \text { Total reactive power supplied by SVC } \\ Q_{S V C} \text { max } & \text { Maximumreactive power supplied by SVC } \\ Q_{S V C} \text { min } & \text { Minimum reactive power supplied by SVC } \\ n_{S V C} & \text { Number of SVCS } \\ \text { pop } & \text { Population } \\ B_{S V C} & \text { Susceptance of SVCS } \\ B_{S V C, \text { max }} & \text { Maximum limit of } B_{S V C}\end{array}$

\section{List of principal symbols (Continued)}

\begin{tabular}{ll}
\hline$B_{\text {svc,min }}$ & Minimum limit of $B_{\text {svc }}$ \\
$y_{s v c}$ & Admittance of SVC \\
Algorithm related symbols & \\
$r l, r 2$ and $r 3$ & Randomly selected indices \\
$\mathrm{NP}$ & Number of population \\
iter & Iteration \\
$\mathrm{fl}$ & Flight length \\
$\mathrm{AP}$ & Awareness probability \\
$\mathrm{F}$ & Mutation constant \\
$\mathrm{CR}$ & Cross-over ratio
\end{tabular}

\section{Acknowledgements}

We are thankful to the Department of Electrical Engineering IIT (ISM) Dhanbad, India for providing the research facilities.

\section{Authors' contributions}

Mr. Nihar Karmakar carried out basic design, simulation work and prepared draft paper. Dr. Biplab Bhattacharyya participated in checking simulation work, results \& discussions, sequence of paper and helped to prepare the manuscript. All authors read and approved the final manuscript.

\section{Funding}

No funding to declare.

\section{Availability of data and materials}

The data that support the findings of this study are available from the corresponding author upon reasonable request.

\section{Declarations}

\section{Competing interests}

The authors declare that they have no known competing financial interests or personal relationships that could have appeared to influence the work reported in this paper.

Received: 10 December 2020 Accepted: 4 June 2021 Published online: 23 August 2021

\section{References}

1. López, J. C., Contreras, J., Muñoz, J. I., \& Mantovani, J. R. S. (2012). A multi-stage stochastic non-linear model for reactive power planning under contingencies. IEEE Transactions on Power Apparatus and Systems, 28, 1503-1514.

2. Granville, S., Pereira, M. V. P., \& Monticelli, A. (1988). An integrated methodology for VAR sources planning. IEEE Transactions on Power Apparatus and Systems, 3(2), 549-557. https://doi.org/10.1109/59.192906.

3. Chattopadhyay, D., Bhattacharya, K., \& Parikh, J. (1995). Optimal reactive power planning and its spot-pricing: An integrated approach. IEEE Transactions on Power Apparatus and Systems, 10(4), 2014-2020. https://doi. org/10.1109/59.476070.

4. Li, F., Zhang, W., Tolbert, L. M., Kueck, J. D., \& Rizy, D. T. (2008). A framework to quantify the economic benefit from local VAR compensation. International Review of Electrical Engineering, 3, 989-998.

5. Bhattacharyya, B., \& Karmakar, N. (2019). Optimal reactive power management problem: A solution using evolutionary algorithms. IETE Technical Review, 37, 540-548.

6. Zhang, C., Chen, H., Ngan, H., Liang, Z., Guo, M., \& Hua, D. (2017). Solution of reactive power optimisation including interval uncertainty using genetic algorithm. IET Generation Transmission and Distribution, 11, 3657-3664.

7. Hong-Zhong, L., Hao-Zhong, C., \& Zheng, Y. (2010). A novel reactive power planning method based on improved particle swarm optimization with static voltage stability. European Transactions on Electrical Power, 20(8), 1129-1137. https://doi.org/10.1002/etep.389. 
8. El-Araby, E. S. E., \& Yorino, N. (2018). Reactive power reserve management tool for voltage stability enhancement. IET Generation Transmission and Distribution, 12, 1879-1888.

9. Raj, S., \& Bhattacharyya, B. (2018). Reactive power planning by oppositionbased grey wolf optimization method. International Transactions on Electrical Energy Systems, 28, 2551.

10. Mahmoudabadi, A., \& Rashidinejad, M. (2013). An application of hybrid heuristic method to solve concurrent transmission network expansion and reactive power planning. International Journal of Electrical Power \& Energy Systems, 45(1), 71-77. https://doi.org/10.1016/j.ijepes.2012.08.074.

11. Ara, A. L., Kazemi, A., Gahramani, S., \& Behshad, M. (2012). Optimal reactive power flow using multi-objective mathematical programming. Scientia Iranica, 19, 1829-1836.

12. Zhang, W., Li, F., \& Tolbert, L. M. (2007). Review of reactive power planning: Objectives, constraints, and algorithms. IEEE Transactions on Power Apparatus and Systems, 22(4), 2177-2186. https://doi.org/10.1109/TPWRS.2 007.907452 .

13. Chattopadhyay, D., \& Chakrabarti, B. B. (2001). Voltage stability constrained Var planning: Model simplification using statistical approximation. International Journal of Electrical Power \& Energy Systems, 23(5), 349-358. https://doi.org/10.1016/S0142-0615(00)00073-9.

14. Thukaram, B. D., \& Parthasarathy, K. (1996). Optimal reactive power dispatch algorithm for voltage stability improvement. International Journal of Electrical Power \& Energy Systems, 18(7), 461-468. https://doi.org/10.1016/ 0142-0615(96)00004-X

15. Udupa, A. N., Thukaram, D., \& Parthasarathy, K. (1999). An expert fuzzy control approach to voltage stability enhancement. International Journal of Electrical Power \& Energy Systems, 21(4), 279-287. https://doi.org/10.1016/ S0142-0615(98)00049-0.

16. Thukaram, D., Parthasarathy, K., Khincha, H. P., Udupa, N., \& Bansilal, A (1998). Voltage stability improvement: Case studies of Indian power networks. Electric Power Systems Research, 44(1), 35-44. https://doi.org/10.101 6/S0378-7796(97)01208-X.

17. Prabavathi, M., \& Gnanadass, R. (2018). Electric power bidding model for practical utility system. Alexandria Engineering Journal, 57(1), 277-286. https://doi.org/10.1016/j.aej.2016.12.002.

18. Khan, Q., Ahmad, F., \& Imran, M. (2017). Congestion management in Indian power transmission system. International Journal Engineering \& Technology, 9(3S), 26-31. https://doi.org/10.21817/ijet/2017/v9i3/170903S005.

19. Karthikeyan, S. P., Palanisamy, K., Rani, C., Raglend, I. J., \& Kothari, D. P. (2009) Security constrained unit commitment problem with operational, power flow and environmental constraints. WSEAS Transactions on Power Systems, $4,53-56$.

20. Murali, M., Kumari, M. S., \& Sydulu, M. (2013). A genetic algorithm based security constrained economic dispatch approach for LMP calculation. International Journal of Energy Science, 3, 116-126.

21. Gupta, S., Singh, N., \& Joshi, K. (2018). Biogeography based novel Al optimization with SSSC for optimal power flow. Majlesi Journal of Electrical Engineering, 12, 39-46.

22. Agrawal, R., Bharadwaj, S. K., \& Kothari, D. P. (2018). Population based evolutionary optimization techniques for optimal allocation and sizing of Thyristor Controlled Series Capacitor. Journal of Electrical Systems and Information Technology, 5, 484-501.

23. Bijwe, P. R., Tare, R. S., \& Kelapure, S. M. (1999). Anticipatory load shedding scheme for loadability enhancement. IEE Proceedings-Generation, Transmission and Distribution, 146, 483-490.

24. Zhao, Y., Irving, M. R., \& Song, Y. (2005). A cost allocation and pricing method for reactive power service in the new deregulated electricity market environment. In 2005 IEEE/PES Transmission \& Distribution Conference \& Exposition: Asia and Pacific, (pp. 1-6).

25. De, M., \& Goswami, S. K. (2010). A direct and simplified approach to powerflow tracing and loss allocation using graph theory. Electric Power Components \& Systems, 38(3), 241-259. https://doi.org/10.1080/15325000903273395.

26. Bhattacharyya, B., Goswami, S. K., \& Bansal, R. C. (2009). Loss sensitivity approach in evolutionary algorithms for reactive power planning. Electric Power Components \& Systems, 37(3), 287-299. https://doi.org/10.1080/1532 5000802454468

27. Karmakar, N. \& Bhattacharyya, B. (2020). Optimal reactive power planning in power transmission network using sensitivity based bi-level strategy. Sustainable Energy, Grids and Networks, 23, 100383. https://doi.org/10.1016/j. segan.2020.100383.
28. Gao, B., Morison, G. K., \& Kundur, P. (1992). Voltage stability evaluation using modal analysis. IEEE Transactions on Power Apparatus and Systems, 7(4) 1529-1542. https://doi.org/10.1109/59.207377.

29. Eghbal, M., Yorino, N., El-Araby, E. E., \& Zoka, Y. (2008). Multi-load level reactive power planning considering slow and fast VAR devices by means of particle swarm optimisation. IET Generation Transmission and Distribution, 2, 743-751.

30. Wolpert, D. H., \& Macready, W. G. (1997). No free lunch theorems for optimization. IEEE Transactions on Evolutionary Computation, 1(1), 67-82. https://doi.org/10.1109/4235.585893.

31. Li, Y., Li, X., \& Li, Z. (2017). Reactive power optimization using hybrid CABCDE algorithm. Electric Power Components \& Systems, 45(9), 980-989. https:// doi.org/10.1080/15325008.2017.1311387.

32. Dey, B., Bhattacharyya, B., \& Devarapalli, R. (2020). A novel hybrid algorithm for solving emerging electricity market pricing problem of microgrid. International Journal of Intelligent Systems Wiley, 36, 919-961.

33. Effatnejad, R., Aliyari, H., \& Savaghebi, M. (2017). Solving multi-objective optimal power flow using modified GA and PSO based on hybrid algorithm. Journal of Operation and Automation in Power Engineering, 5(1), $51-60$.

34. Karmakar, N., Saurav, R., \& Bhattacharyya, B. (2020). Hybrid Intelligence Technique for Reactive Power Planning using FACTS devices. In 2020 International Conference on Emerging Frontiers in Electrical and Electronic Technologies (ICEFEET), (pp. 1-6). Patna India: IEEE.

35. Hu, B., Wang, H., \& Yao, S. (2017). Optimal economic operation of isolated community microgrid incorporating temperature controlling devices. Protection and Control of Modern Power Systems, 2(1), 6. https://doi.org/10.11 86/s41601-017-0037-1.

36. Wu, Y., Rongling, C., Chunquan, L., Leyingyue, Z., \& Zhiling, C. (2020). Hybrid symbiotic differential evolution moth-flame optimization algorithm for estimating parameters of photovoltaic models. IEEE Access, 8, 156328156346. https://doi.org/10.1109/ACCESS.2020.3005711.

37. Storn, R., \& Price, K. (1997). Differential evolution-a simple and efficient heuristic for global optimization over continuous spaces. Journal of Global Optimization, 11(4), 341-359. https://doi.org/10.1023/A:1008202821328.

38. Askarzadeh, A. (2016). A novel metaheuristic method for solving constrained engineering optimization problems: Crow search algorithm. Computers and Structures, 169, 1-12. https://doi.org/10.1016/j.compstruc.2016.03.001.

39. Khalilpourazari, S., \& Seyed Hamid Reza, P. (2019). Sine-cosine crow search algorithm: theory and applications, (pp. 1-18). Neural Computing and Applications Springer.

40. Mirjalili, S., \& Lewis, A. (2016). The whale optimization algorithm. Advances in Engineering Software, 95, 51-67. https://doi.org/10.1016/j.advengsoft.2016.01.008.

41. Gnanadass, R., Venkatesh, P., \& Padhy, N. P. (2004). Evolutionary programming based optimal power flow for units with non-smooth fuel cost functions. Electric Power Components \& Systems, 33(3), 349-361. https:// doi.org/10.1080/15325000590474708.

42. Venkatesh, B. (1999). Optimal reactive power planning and scheduling through multi objective fuzzy LP and ANN. Anna University India.

43. Arul, P. (2014). Application and analysis of intelligent techniques towards optimal power flow problem. Anna University India.

44. Derrac, J., García, S., Molina, D., \& Herrera, F. (2011). A practical tutorial on the use of nonparametric statistical tests as a methodology for comparing evolutionary and swarm intelligence algorithms. Swarm and Evolutionary Computation, 1(1), 3-18. https://doi.org/10.1016/j.swevo.2011.02.002. 